\title{
BIOTESTAMENTO: APONTAMENTOS ACERCA DA EXPERIENCIA ITALIANA A LUZ DO PROJETO DE LEI No. 1142/2017
}

\section{Marcelo Fernando Quiroga Obregón ${ }^{1}$ Anna Paula Iuliano de Souza ${ }^{2}$}

\section{Resumo}

Este artigo pretende demonstrar a experiência italiana no que se refere aos instrumentos jurídicos de autodeterminação do paciente nas escolhas de fim de vida, à luz do Projeto de Lei italiano no. 1142/2017, relativo à regulamentação do denominado Biotestamento, aprovado em abril de 2017, na Câmara dos Deputados e, atualmente, em discussão no Senado italiano. A proposta de introduzir no ordenamento jurídico italiano o instituto do Biotestamento se apresenta relevante a partir de casos concretos, de elevada exposição pública, que reacendeu os debates sobre o direito de autodeterminação e sobre a legalização da eutanásia. Interessa, portanto, a este trabalho, percorrer a discussão em torno do referido projeto de lei, por meio de pesquisa bibliográfica, pontuando conceitos e debates que gravitam a temática, dentro da ótica de autores italianos e de instituições interessadas no tema.

Palavras-chave: Autodeterminação. Regulamentação. Biotestamento. Projeto de lei italiano. Decisões pessoais de fim de vida.

\section{INTRODUÇÃO}

O debate sobre a legalização da eutanásia, frequentemente, assume especial destaque na agenda política de um país a partir de casos emblemáticos que envolvem o tema. Na Itália, alguns casos recentes lançaram nova luz ao assunto e alcançaram o parlamento italiano que, atualmente, discute a aprovação de um projeto de lei relativo ao denominado Biotestamento, ou seja, documento que contém declarações antecipadas de vontade sobre tratamentos sanitários em situações terminais.

Recentemente, no início de 2017, a discussão relativa a decisões pessoais de fim de vida reacendeu-se na Itália diante do caso de suicídio assistido de um cidadão italiano na Suíça. Conhecido como "Caso dj Fabo", a

\footnotetext{
${ }^{1}$ Doutor em Direitos e Garantias Fundamentais pela Faculdade de Direito de Vitória - FDV. Coordenador Acadêmico do curso de especialização em Direito Marítimo e Portuário da Faculdade de Direito de Vitória - FDV. Professor de Direito Internacional e Direito Marítimo e Portuário nos cursos de graduação e pós-graduação da Faculdade de Direito de Vitória - FDV. E-mail: mfqobregon@yahoo.com.br

${ }^{2}$ Graduada em Ciências Sociais pela Universidade Federal do Espírito Santo - UFES. Graduada em Direito pela Faculdade de Direito de Vitória - FDV.E-mail: anna.iuliano@hotmail.com
} 
história do jovem italiano, Fabiano Antoniani, cego e em estado vegetativo desde 2014, em decorrência de um acidente automobilístico, tornou-se o símbolo da atual luta pela legalização da eutanásia e regulamentação do Testamento Biológico na Itália.

Nesse contexto, em abril de 2017, foi aprovado pela Câmara dos Deputados italiana o Projeto de Lei responsável por regulamentar o Testamento Biológico. Apesar de silente com relação à eutanásia, a aprovação do referido projeto representa um ponto forte no percurso da efetivação do direito à autodeterminação em relação às escolhas concernentes à própria saúde.

A elaboração deste trabalho percorreu, inicialmente, a narrativa resumida sobre três casos de elevada exposição pública na Itália, com o objetivo de demonstrar o contexto sobre o qual se desenvolve o tema.

Em seguida, por meio de pesquisa bibliográfica e legislativa, foi possível descrever a situação do projeto de lei italiano que regulamenta o Biotestamento e expor os conceitos de Consentimento Informado, Biotestamento ou Declarações Antecipadas de Vontade, eutanásia e obstinação terapêutica, sob a ótica de instrumentos normativos e da doutrina.

Dessa forma, ao ilustrar a experiência italiana em tramitação, pretende-se estabelecer um panorama atualizado sobre o tema, de forma a contribuir para a discussão da regulamentação de instrumentos jurídicos relativos a decisões de fim de vida.

\section{CASOS EMBLEMÁTICOS}

Fabiano Antoniani, conhecido como “dj Fabo", morreu na Suíça em 27 de fevereiro de 2017, por meio de um procedimento denominado suicídio assistido. O jovem, cego e em estado vegetativo desde 2014, em decorrência de um acidente automobilístico, percorreu um caminho realizado por muitos italianos até o território suíço, para se submeter ao denominado suicídio assistido.

Segundo a Associação Luca Coscioni, ${ }^{3}$ referência em território italiano na promoção da liberdade de pesquisa científica e de afirmação dos direitos humanos, civis e políticos das pessoas doentes e inválidas nas escolhas de fim de vida, a cada dia, um italiano emigra até a Suíça em busca do referido procedimento. ${ }^{4}$ Tal fenômeno, que ganhou o nome de "turismo da morte", 5 difundiu-se em decorrência da previsão no ordenamento jurídico suíço de punição ao suicídio assistido apenas quando cometido por motivos egoísticos, conforme

\footnotetext{
${ }^{3}$ Disponível em: <https://www.associazionelucacoscioni.it/chi-siamo/associazione/>.

$4 \quad$ Disponível em:

<http://www.repubblica.it/cronaca/2017/04/20/news/eutanasia_un_italiano_al_giorno_verso_la_svizzera_per_morire$163482930 />$.

5 Disponível em: <https://www.swissinfo.ch/ita/editoriale_dibattito-sulla-morte--svizzera--un-ideale-per-il-suicidioassistito/42277790>.
} 
prescrito pelo art. 115 do Código Penal do referido país.

Diferentemente, a morte do italiano Piergiorgio Welby ${ }^{6}$ foi considerada um caso de eutanásia passiva, realizada em território italiano. Acometido por uma doença degenerativa, permaneceu ligado ao respirador mecânico de 1997 a 2006, quando conseguiu interromper, com a ajuda de um médico, o tratamento que o mantinha vivo, mesmo diante da frustação de sua longa batalha jurídica contra a obstinação terapêutica e a favor do direito de autodeterminação.

Já Eluana Englaro, ${ }^{7}$ italiana que viveu em estado vegetativo por 17 anos, resultado de um acidente automobilístico, conseguiu em 2009 a interrupção do tratamento de alimentação artificial, após uma longuíssima luta de sua família nos tribunais para obter a suspensão da alimentação e da hidratação forçada.

Em brevíssima síntese, mas suficiente para o escopo deste artigo, a narrativa de três casos emblemáticos e de grande eco midiático na Itália ilustra, superficialmente, o contexto italiano no qual se desenvolvem as controvérsias relativas a instrumentos jurídicos de autodeterminação.

A análise dos casos narrados indica que a regulamentação do Biotestamento seria suficiente para tutelar a dignidade humana em tema de autodeterminação, de forma a contribuir para suavizar a angústia dessas pessoas e de seus familiares que, nessas situações, se sentem não tutelados pelo próprio Estado.

\section{APONTAMENTOS ACERCA DO PROJETO DE LEI RELATIVO A NORMAS EM MATÉRIA DE CONSENTIMENTO INFORMADO E DE DECLARAÇÕES DE VONTADE ANTECIPADAS NOS TRATAMENTOS SANITÁRIOS}

Atualmente, a Itália não conta com uma lei que regulamenta a eutanásia e o Testamento Biológico, no entanto, quanto a este último, alguns passos concretos foram dados com a aprovação, na Câmara dos Deputados, do projeto de lei que trata de decisões pessoais de fim de vida e que, agora, depende do Senado para aprovação definitiva.

Aprovado na Câmara dos Deputados, em abril de 2017, o Projeto de Lei no ${ }^{\circ} 1.142,{ }^{8}$ denominado "Normas em matéria de consentimento informado e de declarações de vontade antecipadas nos tratamentos sanitários", resultado de diversas outras propostas apresentadas na última década à Câmara dos Deputados,

\footnotetext{
${ }^{6}$ São muitos os documentos que tratam do caso Welby, dentre eles: <https://www.associazionelucacoscioni.it/il-caso-giuridicodi-piergiorgio-welby/>; <http://www.treccani.it/enciclopedia/eutanasia_\%28Il-Libro-dell\%27Anno\%29/>.

O caso Englaro inspirou o filme italiano Bella addormentata, de Marco Bellocchio. Informações em: <http://www.mymovies.it/film/2012/bellaaddormentata/>; informações sobre o caso disponíveis em: https://www.associazionelucacoscioni.it/notizie/rassegna-stampa/approfondimenti-sul-caso-englaro/

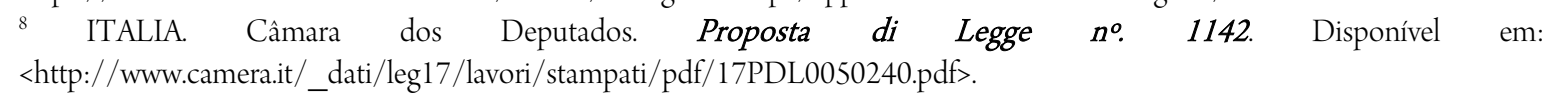


coloca-se, atualmente, como referência legislativa quanto aos temas consentimento informado e declarações antecipadas de tratamento, esta última amplamente denominada na Itália de "Testamento Biológico" ou "Biotestamento".

O projeto de lei apresenta-se como documento normativo de tutela da vida e da saúde do indivíduo. Desse modo, estabelece que "[...] nenhum tratamento sanitário pode ser iniciado ou prosseguido se privado do consenso livre e informado da pessoa interessada, exceto nos casos expressamente previstos em lei".

A orientação do projeto encontra fundamento nos princípios constitucionais da primazia do indivíduo em relação ao Estado, da inviolabilidade da liberdade constitucional e do direito fundamental à saúde, previstos na Constituição da República Italiana ${ }^{9}$ e na Carta de Direitos Fundamentais da União Europeia.

De fato, o art. $32^{10}$ da Constituição da República Italiana, além de consagrar a tutela da saúde como direito fundamental, prevê, em sua segunda parte, que "[...] ninguém pode ser obrigado a um determinado tratamento sanitário salvo nos casos previstos em lei" e, ainda, que "[...] a lei não pode em nenhum caso violar os limites impostos pelo respeito da pessoa humana”.

A dicção da norma é entendida como condicionada pelo art. $2^{011}$ do texto constitucional, ao dispor sobre o princípio personalista, segundo o qual, “[...] a República reconhece e garante os direitos invioláveis do homem, seja como individuo, seja nas formações sociais onde se desenvolve a sua personalidade". Em conjunto, as normas acima descritas podem ser interpretadas pelo art. $13^{12}$ da Constituição Italiana, quando consagra que "[...] a liberdade pessoal é inviolável”.

Segundo Tiziano Ceccholi, ${ }^{13}$ a partir da interpretação dos dispositivos constitucionais mencionados, emerge a opinião de considerar legítima a escolha de não "se tratar até a morte". Como afirmado pelo autor, a jurisprudência majoritária aceita tal configuração, de tal forma que "[...] explicitamente, em um de seus pronunciamentos, afirmou que da combinação do artigo 32, parágrafo $2^{\circ}$ e artigo 13 da Constituição, deriva não tanto um direito ao suicídio, mas a liberdade de cada indivíduo de escolher se e como tratar-se e, em última análise, se viver ou não".

\footnotetext{
${ }^{9}$ ITALIA. Presidenza del Consiglio dei Ministri. Costituzione Italiana. Disponível em: <http://www.governo.it/costituzioneitaliana/principi-fondamentali/2839>. Acesso em: 12 set. 2017.

${ }^{10}$ Tradução livre de: "Art. 32. La Repubblica tutela la salute come fondamentale diritto dellindividuo e interesse della collettività, e garantisce cure gratuite agli indigenti. Nessuno può essere obbligato a un determinato trattamento sanitario se non per disposizione di legge. La legge non puo in nessun caso violare i limiti imposti dal rispetto della persona umana”.

${ }^{11}$ Tradução livre de: "Art. 20. La Repubblica riconosce e garantisce i diritti inviolabili dell'uomo, sia come singolo sia nelle formazioni sociali ove si svolge la sua personalità, e richiede l'adempimento dei doveri inderogabili di solidarietà politica, economica esociale".

${ }^{12}$ Tradução livre de: "Art. 13. La libertà personale è inviolabile".

${ }^{13}$ CHECCOLI, Tiziano. Brevi note sulla distinzione fra eutanasia ativa e passiva, p. 14. Paper apresentado no Fórum de Biodireito realizado na Universidade de Trento em 2008. Disponível em:
} 
É nesse contexto jurídico que se desenvolve o projeto de lei cujo conteúdo, ao longo de oito artigos, dispõe sobre o consentimento informado, sobre as disposições antecipadas de tratamento, sobre a situação dos menores e dos incapazes e sobre a relação entre médico e paciente relativa à planificação compartilhada de tratamento.

Atualmente em discussão no Senado Italiano, sob a denominação de Disegno di Legge no $2.801,{ }^{14}$ a proposta de lei estabelece importantes conceitos, que serão a seguir abordados, os quais demonstram o posicionamento do legislador sobre o tema.

\section{TERMO DE CONSENTIMENTO INFORMADO}

O Projeto de Lei no 1.142 dispõe sobre o consentimento informado, conceituando-o como o documento com o qual a pessoa capaz tem direito de recusar, no todo ou em parte, qualquer exame diagnóstico ou tratamento sanitário ou de atos singulares do próprio tratamento indicado pelo médico para a sua patologia.

Quanto à forma, o Termo de Consentimento pode ser escrito ou registrado em vídeo ou expresso por meio de qualquer dispositivo que permita à pessoa, quando inválida, se comunicar. $\mathrm{O}$ termo pode ser modificado a qualquer momento, mesmo quando possa acarretar interrupção do tratamento, inclusive relativo à nutrição e à hidratação artificial.

No entanto, o projeto de lei esclarece que a recusa ou a renúncia ao tratamento sanitário indicado pelo médico não significa abandono terapêutico. É garantido o envolvimento do médico e o fornecimento de cuidados paliativos e, em situações de emergência ou de urgência, o médico assegura a assistência sanitária indispensável, sempre que possível, respeitando a vontade do paciente.

Também a jurisprudência da Corte Constitucional Italiana já se posicionou sobre o assunto, fornecendo alguns parâmetros para conceituar o consentimento informado, esclarecendo que o instituto encontra fundamento constitucional, constituindo-se como:

[...] expressão da adesão consciente ao tratamento sanitário proposto pelo médico e [que] se configura como verdadeiro e próprio direito da pessoa, encontra fundamento nos princípios expressos pelo art. $2^{\circ} \mathrm{da}$ Constituição, que tutela e promove os direitos fundamentais, e nos arts. 13 e 32, os quais estabelecem, respectivamente, que 'a liberdade da pessoa é inviolável' e que 'ninguém pode ser obrigado a um determinado tratamento sanitário, senão por disposição de lei. ${ }^{15}$

<http://www.jus.unitn.t//dsg/convegni/2008/forum_biodiritto/papers/checcoli.pdf $>$. Acesso em: 12 set. 2017.

14 ITÁLIA. Senato italiano. Atto Senato $\boldsymbol{n}^{\text {o. }}$ 2801. Disponível em: <http://www.senato.it/leg/17/BGT/Schede/Ddliter/47964.htm>.

${ }^{15}$ ITÁLIA. Corte Constitucional italiana. Sentenza no. 438 del 2008. Tradução livre de: "[...] consenso informato, inteso quale espressione della consapevole adesione al trattamento sanitario proposto dal medico, si configura quale vero e proprio diritto della persona e trova fondamento nei principi espressi nell'art. 2 della Costituzione, che ne tutela e promuove i diritti fondamentali, e 
A definição proposta pela doutrina italiana auxilia a compreensão do tema de forma mais abstrata e flexível, demonstrando-se, dessa forma, mais bem apropriada à "[...] concretude de cada situação clínica e aos tempos e modos da ação médica". ${ }^{16}$ Nesse sentido, segundo Alessandro Felici (2008, p. 21), o consentimento informado é:

[...] resultado de um processo comunicativo entre médico e paciente, tendo por objetivo assegurar a adesão (ou não adesão) livre, efetiva, participada, consciente e voluntária do paciente no iter diagnóstico e terapêutico proposto pelo próprio médico, para a resolução ou o melhoramento do seu contingente problema de saúde, quer seja na acepção psicofísica e/ou biossocial. ${ }^{17}$

Essa relação médico-paciente, em termos de consentimento informado, encontra previsão no $₫ 2^{\circ}$, do art. $1^{\circ}$ do Projeto de Lei no. 1.142/2017, que permite a autonomia do paciente, inclusive para inserir, nessa relação, seus familiares, cônjuge, companheiro estável ou, ainda, outra pessoa de sua confiança, nos seguintes termos:

Art. $1^{\circ}, \mathbb{} 2^{\circ}$ : Promove-se e valoriza-se a relação de cuidado e de confiança entre paciente e médico, cujo ato fundador é o consentimento informado, no qual se encontram a autonomia decisória do paciente e a competência, a autonomia profissional e a responsabilidade do médico. Em tal relação, estão envolvidos, se o paciente o desejar, também os seus familiares, a parte da união civil, o convivente ou, ainda, uma pessoa de sua confiança. ${ }^{18}$

Reforça tal concepção a postura assumida pelo Conselho Italiano de Medicina de Florença (Ordine dei Medici di Firenze), da qual se extrai a importância relevada à comunicação entre médico e paciente, dando ênfase ao fornecimento exaustivo de informações por parte do médico. Nesse sentido, fica claro que a informação dada ao paciente constitui parte integrante da prestação médica, de tal forma que, “[... a legitimação da atividade do médico não encontra mais seu fundamento no prestígio e na autoridade do profissional, mas, somente e exclusivamente, no consentimento informado do paciente". ${ }^{19}$

Por sua vez, o Código de Deontologia Médica italiano ${ }^{20}$ dispõe de sete artigos para tratar da

negli artt. 13 e 32 della Costituzione, i quali stabiliscono, rispettivamente, che la libertà personale è inviolabile', e che 'nessuno può essere obbligato a un determinato trattamento sanitario se non per disposizione di legge". Disponível em: <http://documenti.camera.it/Leg17/Dossier/Pdf/COST252.Pdf>

16 MIRABELLI, Cesare. Audizione alla commissione sanità del Senato, 2017, p. 1. Disponível em: <http://www.senato.it/leg/17/BGT/Schede/Ddliter/documenti/47964_documenti.htm>. Acesso em: 11 set. 2017.

${ }^{17}$ Tradução livre de: Il Consenso Informato è un processo comunicativo interativo tra il sanitário e il suo assistito, che ha come scopo quello di assicurare l'adesione (o la non adesione) libera, effettiva, partecipata, consapevole e volontaria del paziente alliter diagnostico e terapeutico propostogli dal proprio medico curante per la risoluzione o il miglioramento del suo contingente problema di salute, che sia esso nella sua accezione psico-fisica e/o bio-sociale(2008, p. 21).

${ }^{18}$ Tradução livre de: "Art. I, Is 20. È promossa e valorizzata la relazione di cura e di fiducia tra paziente e medico il cui atto fondante è il consenso informato nel quale si incontrano l'autonomia decisionale del paziente e la competenza, lautonomia professionale e la responsabilità del medico. In tale relazione sono coinvolti, se il paziente lo desidera, anche i suoi familiari o la parte dell'unione civile o il convivente ovvero una persona di sua fiducia”.

19 Disponível em: <http://www.ordine-medici-firenze.it/index.php/faq-domande-frequenti/102-consenso-informato>. Acesso em: 12 set. 2017.

${ }^{20}$ FEDERAZIONE NAZIONALE DEGLI ORDINI DEI MEDICI CHIRURGHI E DEGLI ODONTOIATRI. Codice di Deontologia 
comunicação entre médico e paciente. Expressa-se, em seu art. 35, sobre o consentimento informado, conceituando-o da seguinte forma:

\begin{abstract}
Art. 35. Consentimento e dissenso informado
A aquisição do consentimento ou do dissenso informado é um ato de específica e exclusiva competência médica não delegável. $O$ médico não empreende nem prossegue procedimento diagnóstico e/ou intervenções terapêuticas sem a preliminar aquisição do consentimento informado ou em presença do dissenso informado. O médico obtém, de forma escrita e assinada, ou com outras modalidades de equivalente eficiência documental, o consentimento ou o dissenso do paciente, nos casos previstos pelo ordenamento e pelo código e naqueles presumivelmente marcados pelo elevado risco de mortalidade ou de incidência relevante sobre a sua integridade psicofísica. $\mathrm{O}$ médico leva em adequada consideração as opiniões expressas pelo menor em todos os processos decisórios que the digam respeito. ${ }^{21}$
\end{abstract}

Assim entendido, a partir das concepções fornecidas tanto pela doutrina e pela jurisprudência italiana, quanto pelas disposições normativas em projeto, resta evidente que o consentimento informado, como manifestação de vontade, não deve ser tratado somente como requisito de legalidade, pelo contrário, deve ser considerado um direito fundamental garantido constitucionalmente.

\title{
DECLARAÇÕES ANTECIPADAS DE TRATAMENTO OU BIOTESTAMENTO
}

O art. $3^{\circ}$ do Projeto de Lei no. 1.142 prevê e disciplina as Disposições antecipadas de tratamento, definindo-as da seguinte forma:

Art. $3^{\circ}$. (Disposições antecipadas de tratamento)

1. Toda pessoa maior de idade e capaz de entender e de querer, em antecipação a uma eventual futura incapacidade de autodeterminar-se, pode, por meio de DAT, exprimir as próprias convicções e preferências em matéria de tratamentos sanitários, bem como o consentimento ou a recusa relativa a escolhas diagnósticas ou terapêuticas e a específicos tratamentos sanitários, compreendidas as práticas de nutrição e de hidratação artificial. Além disso, pode indicar uma pessoa de confiança, denominada fiduciário, que o represente nas relações com o médico e com as estruturas sanitárias. ${ }^{22}$

Tal definição, assim exposta, suscitou divergências entre os diversos sujeitos interessados na temática, no

\footnotetext{
<https://portale.fnomceo.it/fnomceo/Codice+di+Deontologia+Medica+2014.html?t=a\&id=115184>. Acesso em: 15 set. 2017.

${ }^{21}$ Tradução livre de: Articolo 35 - consenso e dissenso informato: L'acquisizione del consenso o del dissenso è un atto di specifica competenza del medico, non delegabile. Il medico non intraprende né prosegue in procedure diagnostiche e/o interventi terapeutici senza la preliminare acquisizione del consenso informato o in presenza di dissenso informato. Il medico acquisisce in forma scritta e sottoscritta o con altre modalità di pari efficacia documentale, il consenso o il dissenso del paziente, nei casi previsti dall'ordinamento e dal Codice e in quelli prevedibilmente gravati da elevato rischio di mortalità o di esiti che incidano in modo permanente sullintegrità psico-fisica. è un atto medico non delegabile. Il medico tiene in adeguata considerazione le opinioni espresse dal minore in tutti i processi decisionali che lo riguardano.

${ }^{22}$ Tradução livre de: "Art. 30. (Disposizioni anticipate di trattamento). 1. Ogni persona maggiorenne e capace di intendere e di volere, in previsione di un'eventuale futura incapacità di autodeterminarsi, puó, attraverso le DAT, esprimere le proprie convinzioni e preferenze in materia di trattamenti sanitari, nonché il consenso o il rifiuto rispetto a scelte diagnostiche o terapeutiche e a singoli trattamenti sanitari, comprese le pratiche di nutrizione e idratazione artificiali. Indica altresi una persona di sua fiducia, di seguito denominata fiduciario, che ne faccia le veci e la rappresenti nelle relazioni con il medico e con le strutture sanitarie”.
} 
que diz respeito ao termo "declarações" que, aparentemente, se contrapõe a "disposições". Como visto, o art. $3^{\circ}$ recebe o título de "Disposições Antecipadas de Tratamento", não obstante o título do próprio projeto se refira a "Declarações de Vontade Antecipadas".

Conforme observa Cesare Mirabelli, ${ }^{23}$ presidente emérito da Corte Constitucional italiana, a expressão declarações é, de fato, aquela mais apropriada, sobretudo, quando se considera tanto a Convenção de Oviedo, que se utiliza da expressão "desejos", quanto o Código de Deontologia Médica, pois,

[...] segundo uma visão correta, trata-se de declarações que manifestam a intenção da pessoa caso se verifiquem circunstâncias ainda indefinidas ou indefiníveis nos domínios de sua pontual concretude, mas não no sentido de vontade negocial que dispõem e impõem ao médico um comportamento ativo ou omissivo que pode ser, até mesmo, inapropriado [...]. ${ }^{24}$

Nesse ponto, esclarece o jurista que o termo "disposições" se apresenta envolvido em excesso de formalismo e de burocratização. Tal opinião diverge da posição expressa pela Associação Cittadinanza Attiva, 25 organização italiana sem fins lucrativos que promove o ativismo dos cidadãos na tutela de seus direitos, segundo a qual com o termo se "dá mais força às vontades da pessoa" sendo, portanto, mais adequado.

Carlo Petrini, ${ }^{26}$ membro do Instituto Superior de Saúde da Itália, convergindo com a posição adotada por Mirabelli, reafirma a sugestão do uso do termo "declarações", primeiro, porque a expressão "disposições" equivale à ordem, enquanto "declarações" evidencia o seu valor não vinculante e, segundo, porque se apresenta em consonância com importantes documentos, como a Convenção de Oviedo e o Código de Deontologia Médica italiano. Portanto, o título do artigo terceiro, já transcrito, deveria ser corrigido para "Declarações Antecipadas de Tratamento".

Apesar das divergências relacionadas com a terminologia correta, discutindo-se entre "disposições e declarações", o conceito de Declarações Antecipadas de Tratamento se apresenta uniforme entre os diversos sujeitos interessados no tema.

O Dossier consultivo n $392 / 1{ }^{27}$ de 10 de março de 2017, elaborado na Câmara dos Deputados, refere-

23 MIRABELLI, Cesare. Audizione alla commissione sanità del Senato, 2017, p. 2. Disponível em: <http://www.senato.it/leg/17/BGT/Schede/Ddliter/documenti/47964_documenti.htm>. Acesso em: 11 set. 2017.

${ }^{24}$ Tradução livre de: "(...) secondo una visione correta si tratta di dichiarazioni che manifestano la intenzione della persona al verificarsi di circostanze non del tutto definite né definibili nei risvolti della loro puntuale concretezza. Non manifestazioni di volontà negoziale che 'dispongono' ed impongono al medico un comportamento attivo o omissivo che può essere inappropriato, anche se non 'palesemente incongruo'”.

25 Parecer da Associação italiana Cittadinanza Attiva. 2017. Disponível em: $<$ http://www.senato.it/application/xmanager/projects/leg17/attachments/documento_evento_procedura_commissione/files /000/005/128/CITTADINANZATTIVA.pdf>. Acesso em: 15 set. 2017.

26 Parecer do Istituto Superiore di Sanità, $2017 . \quad$ Disponível em: <http://www.senato.it/application/xmanager/projects/leg17/attachments/documento_evento_procedura_commissione/files /000/005/154/PETRINI.pdf $>$. Acesso em 15 set. 2017.

27 ITÁlIA. Câmara dos Deputados. Dossier no 392/1 di 10 marzo 2017 . Disponível em: $<$ http://documenti.camera.it/Leg17/Dossier/Pdf/AS0233A.Pdf>. Acesso em: 12 set. 2017. 
se às Disposições Antecipadas de Tratamento como:

[...] expressão de vontade, mediante um documento escrito por um sujeito, fornecida em condições de lucidez mental, na qual são ditadas indicações antecipadas de tratamento acerca das terapias que pretende ou não pretende seguir na eventualidade de encontrar-se na condição de incapacidade de exercitar o próprio direito de consentir ou não os cuidados propostos para doenças ou lesões traumáticas cerebrais irreversíveis ou invalidantes, doenças que obriguem a tratamentos permanentes com equipamentos ou sistemas artificiais que impeçam uma vida normal. ${ }^{28}$

Interessante notar que o Código de Deontologia Médica Italiano dispõe sobre as Declarações Antecipadas de Tratamento de forma semelhante, porém acrescenta que o paciente deverá obter informações médicas prévias documentadas e ainda destaca que compete ao médico avaliar a congruência lógica das declarações do assistido, conforme se verifica no art. 38, a seguir transcrito:

Art. 38 - Declarações antecipadas de tratamento

O médico considera as declarações antecipadas de tratamento expressas em forma escrita, firmadas e datadas, por parte de pessoa capaz, e decorrentes de informação médica da qual existam traços documentais. A declaração antecipada de tratamento comprova a liberdade e a consciência da escolha sobre os procedimentos diagnósticos e/ou sobre as intervenções terapêuticas que se deseja ou não se deseja que sejam aplicadas em condições de total ou grave comprometimento das faculdades cognitivas ou avaliativas que impeçam a atual expressão de vontade. O médico, ao considerar as declarações antecipadas de tratamento, verifica a sua congruência lógica e clínica com a condição prática e inspira a própria conduta, respeitando a dignidade e a qualidade de vida do paciente, dando clara expressão na documentação sanitária. $\mathrm{O}$ médico coopera com o representante legal buscando o melhor interesse do paciente e, em caso de contraste, faz uso do julgamento arbitral previsto no ordenamento. Em relação às condições clínicas, procede tempestivamente aos cuidados considerados indispensáveis e indeferíveis. ${ }^{29}$

Outro ponto que merece esclarecimentos refere-se à delegação. A redação do art. $3^{\circ}$ do projeto de lei deixa evidente que a autodeterminação do paciente inclui também a indicação de um terceiro, denominado fiduciário. Seguindo o raciocínio de Federico Pizzetti (2008, p. 8), ${ }^{30}$ ao incluir tal possibilidade, seria possível

\footnotetext{
${ }^{28}$ Tradução livre de: "Fa riferimento all'espressione di volontà, mediante un documento scritto, da parte di un soggetto, fornita in condizioni di lucidità mentale, con il quale vengono dettate indicazioni anticipate di trattamento circa le terapie che intende o non intende seguire nell'eventualità in cui dovesse trovarsi nella condizione di incapacità ad esercitare il proprio diritto ad acconsentire o meno alle cure proposte per malattie o lesioni traumatiche cerebrali irreversibili o invalidanti, malattie che costringano a trattamenti permanenti con macchine o sistemi artificiali che impediscano una normale vita di relazione". Disponível em: <http://documenti.camera.it/Leg17/Dossier/Pdf/AS0233A.Pdf>. Acesso em: 12 set. 2017.

${ }^{29}$ Tradução livre de: "Articolo 38 - dichiarazioni anticipate di tratamento: Il medico tiene conto delle dichiarazioni anticipate di trattamento espresse in forma scritta, sottoscritta e datata da parte di persona capace e successive a un informazione medica di cui resta traccia documentale. La dichiarazione anticipata di trattamento comprova la libertà e la consapevolezza della scelta sulle procedure diagnostiche e/ o sugli interventi terapeutici che si desidera o non si desidera vengano attuati in condizioni di totale o grave compromissione delle facoltà cognitive o valutative che impediscono l'espressione di volontà attuali. Il medico, nel tenere conto delle dichiarazioni anticipate di trattamento, verifica la loro congruenza logica e clinica con la condizione in atto e ispira la propria condotta al rispetto della dignità e della qualità di vita del paziente, dandone chiara espressione nella documentazione sanitaria. Il medico coopera con il rappresentante legale perseguendo il migliore interesse del paziente e in caso di contrasto si avvale del dirimente giudizio arbitrale previsto dallordinamento e, in relazione alle condizioni cliniche, procede comunque tempestivamente alle cure ritenute indispensabili e indifferibill.

${ }^{30}$ PIZZETTI, Federico G. Alle frontiere della vita: il testamento biologico tra valori costituzionali e promozione della persona,
} 
afirmar a existência de dois tipos de testamento biológico: de um lado, as declarações que ditam as instruçôese, de outro, as declarações que indicam a delegação, de modo que:

Através das primeiras, se podem indicar 'tratamentos ou explícitas terapias que deseja excluir ou incluir no curso da doença e, sobretudo na fase terminal', segundo uma ampla variedade de conteúdos específicos, assim como se pode, igualmente, fornecer uma ampla gama de indicações de outro gênero, mesmo não estritamente médicas, como assistência religiosa que deseja receber, intenção de doar os próprios órgãos para fins de didática ou pesquisa; escolhas de sepultamento, modalidades de humanização do sofrimento e da morte (recurso a cuidados paliativos, preferência por assistência hospitalar ou domiciliar, e assim por diante) (2008, p. 8).

Com relação ao segundo tipo, referente à delegação ao fiduciário, Pizzetti (2008, p. 8) estabelece que, por meio de tal possibilidade:

[...] se atribui ao interessado a faculdade de designar uma pessoa de confiança a qual se confere o compromisso de decidir em seu nome, quando não será mais capaz de fazê-lo autonomamente em decorrência do agravamento de uma condição patológica superveniente.

Cumpre anotar que o projeto de lei silencia a respeito da responsabilidade civil do médico e da equipe sanitária diante da recusa, por parte do paciente, de se submeter a determinados tratamentos. Conforme apontado pela Sociedade Italiana de Cuidados Paliativos, ${ }^{31}$ o texto de lei que trata de diretivas antecipadas de tratamento deve dispor sobre a responsabilidade civil no sentido de isentar completamente a equipe médica na referida situação.

Por fim, o Dossier consultivo no 392,32 elaborado em 6 de fevereiro de 2016, pela Comissão de Estudos da Câmara de Deputados Italiana, cuida de estabelecer algumas diferenças entre as Declarações Antecipadas de Tratamento (DATs) e o denominado Biotestamento ou Testamento Biológico. Nesse sentido, estabelece que:

As diferenças entre DATs e testamento biológico se exprimem seja no plano subjetivo, seja no plano objetivo: enquanto as DATs podem conter indicações de vontade para qualquer tratamento sanitário - desde de uma cirurgia estética até um procedimento de suporte vital - o testamento biológico, tem conteúdo mais restrito relatando, normalmente, disposições relativas unicamente aos procedimentos de suporte vital e aos outros tratamentos capazes de permitir um prolongamento artificial da vida. Neste acrescente-se que, por sua natureza testamentária, geralmente, é explicitada a vontade do sujeito sobre questões relativas ao fim de vida. ${ }^{33}$

Milano: Giuffré Editore, 2008, p. 8.

${ }^{31}$ SOCIETÀ ITALIANA DI CURE PALLIATIVE (SICP). Documento sulle direttive anticipate, v. de 9.11.2006. Disponível em: <http://www.sicp.it/web/eventi/SICP/documenti.cfm>.

32 ITÁliA. Câmara dos Deputados. Dossier no 392, de 6 de fevereiro de 2016. Disponível em: <http://documenti.camera.it/Leg17/Dossier/Pdf/AS0233.Pdfs.

${ }^{33}$ Tradução livre de: Le differenze tra le D.A.T. e il testamento biologico si esprimono sia sul piano soggettivo, sia sul piano oggettivo: mentre le D.A.T. possono contenere indicazioni di volontà per qualsiasi trattamento sanitario — da un intervento di chirurgia estetica ad una procedura di sostegno vitale - il testamento biologico, ha un contenuto piu ristretto riportando, normalmente, disposizioni relative unicamente alle procedure di sostegno vitale e agli altri trattamenti in grado di consentire un prolungamento artificiale della vita. A ciò si aggiunga che in esso, proprio per la sua natura "testamentaria", è in genere esplicitata la volontà del soggetto su questioni attinenti al fine vita. 
Tais distinções podem representar importantes pontos de reflexão para o Projeto de Lei no 1.142/2017, ainda carente de aprovação no Senado, pois as expressões Declarações Antecipadas de Tratamento (DATs) e Biotestamento são largamente utilizadas como sinônimos.

\section{EUTANÁSIA}

Como visto, o projeto, atualmente em tramitação no Senado, diz respeito a "Normas em matéria de consentimento informado e de declarações de vontade antecipadas nos tratamentos sanitários", cujo conteúdo ainda se encontra distante da discussão acerca da legalização da eutanásia.

Apesar dos importantes passos alcançados em termos de regulamentação do Biotestamento, a discussão acerca do reconhecimento legal da eutanásia não encontrou terreno fértil para o debate no Parlamento italiano. Atualmente, existem seis propostas de lei sobre a eutanásia, cinco de iniciativa parlamentar e uma de iniciativa popular, que, no entanto, não contam com previsão definida para discussão nas casas parlamentares. ${ }^{34}$

Auxilia a percepção do distanciamento entre Biotestamento e eutanásia o conceito fornecido pela doutrina italiana. Nesse sentido, Pizzetti (2008, p.14) esclarece que eutanásia implica:

[...] um pedido de intervenção ativo (quer direto, como ocorre com a inoculação do veneno por conta de terceiro, quer indireto, como acontece quando o médico coloca à disposição a substância letal em favor do requerente, o qual depois a assume por si só), expresso com a intenção, firme e reiterada, de obter positivamente e 'imediatamente' a morte, em modo tal que possa abreviar forçosamente, por razões piedosas e com a finalidade de aliviar o sofrimento, o tempo da existência em vida da pessoa muito além de quanto o próprio decurso natural da doença proporcionaria, uma vez que não se está mais contrastada ou retardada pela medicina (come ocorre quando se limita a honrar a recusa de cuidados 'salva vida' manifestado pelo doente) $)^{35}$

Visto dessa forma, é possível estabelecer uma primeira diferença: na eutanásia há intenção de imediatidade do resultado morte, subsequente à manifestação da vontade, diferentemente do Biotestamento, no qual ocorre a manifestação de vontade atual do indivíduo sobre evento futuro e incerto de superveniente incapacidade de exprimir seus desejos. Ambos tratam de decisões de fim de vida e autodeterminação, mas diferem quanto ao momento de atuação.

Mesmo sem se estender na diferenciação entre os institutos, para permanecer no escopo do presente

Todas as propostas encontram-se disponíveis
<https://parlamentol7.openpolis.it/argomento_leggi/EUTANASIA/filter_act_leggi_type/DDL/filter_act_ramo/0>
35 Tradução livre de: "L'eutanasia implica, invece, uma richiesta d'intervento ativo (vuoi diretto, come avviene com l'inoculazione
del veleno per opera del terzo, vuoi indireto, come accade con la messa a disposizione della sostanza letale, da parte del medico, a
favore del richiedente, il quale poi provede ad assumerla da sé), expressa com l'intenzione, fermissima e reiterata, di ottenere
positivamente e im-mediatamente"la morte, in modo tale da abbreviare forzosamente, per ragioni pietose e al fine di alleviare le
sofferenze, il tempo dell'esistenza in vita della persona molto più di quanto lo stesso decorso naturale della malattia prevedrebbe,
una volta che non sai più contrastato o rallentato dall'azione della medicina (come sucede quando, invece, ci si limiti a onorare il


estudo, é interessante trazer importantes contribuições conceituais acerca da eutanásia e de temas correlatos. Nesse sentido, vale expor o entendimento da doutrina europeia sobre a definição de eutanásia, eutanásia passiva e suicídio assistido.

Segundo Lars Johan Materstvedt et al. (2004, p. 42), da Associação Europeia de Cuidados Paliativos, dentre as inúmeras definições de eutanásia e de suicídio assistido oferecidas por médicos, devem ser excluídas as ações que digam respeito à eutanásia passiva, tendo em vista que se mostra "inapropriada e inexistente". Da mesma forma, com relação à terminologia eutanásia voluntária, que deve ser abandonada para que não se depreenda que existem outros tipos de eutanásia que não seja a voluntária, pois "a morte medicalizada de uma pessoa sem o seu consenso, seja 'não voluntária' (quando a pessoa não pode consentir), seja 'involuntária' (contra a vontade da pessoa), não é eutanásia: é homicídio. Por isso a eutanásia pode ser somente voluntária”. ${ }^{36}$

De acordo com a posição assumida pela referida Associação, a única eutanásia existente é a ativa e, portanto, recomenda a adoção das seguintes definições:

A eutanásia é a morte solicitada e se define como: a ação de matar intencionalmente uma pessoa, efetuada por um médico, por meio da administração de fármacos, seguindo o pedido voluntário e consciente da própria pessoa.

O suicídio assistido por médico se define como: a ação de ajudar, intencionalmente, por parte de um médico, uma pessoa ao suicídio, colocando a disposição os fármacos para a autoadministração, seguindo o pedido voluntário e consciente da própria pessoa. ${ }^{37}$

$\mathrm{Na}$ doutrina italiana, é comum o uso da definição de eutanásia dividindo-a em ativa e passiva. Nesse sentido, Umberto Veronese (2007, p. 6) apresenta o conceito de eutanásia distinguindo-a em intervenção ativa, que seria a utilização de meios idôneos para o alcance da finalidade morte, e a passiva, que seria a interrupção de tratamentos que mantêm o paciente em vida e, assim, ao cessarem, antecipam a morte. Portanto, para o referido autor:

A eutanásia ativa indica a intervenção de um médico, ou de outra pessoa, destinada a colocar fim na vida do paciente. É o ato de buscar a morte com meios idôneos a não fazer sofrer. A eutanásia passiva refere-se à interrupção de um tratamento terapêutico não mais útil para a melhora do paciente, com o qual alcança o decesso ou a antecipação da morte do doente. Consiste, então, na suspensão daquelas terapias e tratamentos usados para prolongar a vida, definidos como obstinação terapêutica. ${ }^{38}$

rifiuto di cure "Salvavita" manifesto dal malato)".

${ }^{36}$ Tradução livre de: "L'uccisione medicalizzata di una persona senza il suo consenso, sia «non volontaria» (quando la persona non puó acconsentire) sia «involontaria» (contro la volontà della persona), non è eutanasia: è omicidio. Perció l'eutanasia puó essere solo volontaria".

${ }^{37}$ Tradução livre de: "L'eutanasia è l'uccisione su richiesta e si definisce come: L'azione di uccidere intenzionalmente una persona, effettuata da un medico, per mezzo della somministrazione di farmaci, assecondando la richiesta volontaria e consapevole della persona stessa. Il suicidio assistito dal medico si definisce come: L'azione di aiutare intenzionalmente, da parte di un medico, una persona a suicidarsi, rendendo disponibili i farmaci per l'autosomministrazione, assecondando la richiesta volontaria e consapevole della persona stessa”.

38 Tradução livre de: "L'eutanasia attiva indica l'intervento di un medico, o di un'altra persona, volto a porre fine alla vita del paziente. È l'atto di procurare la morte con mezzi idonei a non far soffrire. L'eutanasia passiva riguarda invece l'interruzione di un 
Como visto, a eutanásia não está inserida no projeto de lei de regulamentação do Biotestamento. Mesmo assim, da leitura de diversos casos concretos de autodeterminação de pacientes italianos, é possível verificar que a existência do testamento biológico seria suficiente para o reconhecimento do direito de não se sujeitar à obstinação terapêutica.

Diante do quadro apresentado, é possível afirmar que a aprovação do Projeto de Lei no. 1.142/2017 no Senado, será considerada um passo determinante para a abertura de um diálogo sobre a legalização da eutanásia na Itália.

\section{OBSTINAÇÃO TERAPÊUTICA}

Após expor, sucintamente, as posições e as definições acerca da eutanásia, é possível avançar para a questão relativa à obstinação terapêutica.

O projeto de lei em estudo é resultado de um texto unificado extraído de diversas propostas apresentadas à Câmara de Deputados Italiana, dentre os quais, o primeiro se intitulava "Normas em matéria de consentimento informado e declarações de vontade antecipada nos tratamentos sanitários com a finalidade de evitar a obstinação terapêutica". ${ }^{39}$

A supressão da parte final do título original, que diz respeito à finalidade de evitar a obstinação terapêutica, certamente não compromete a regulamentação nesse sentido, tendo em vista que, por meio do Biotestamento, é possível declarar a vontade de não se submeter a inúmeros tratamentos que configurem obstinação terapêutica.

No entanto, tal omissão não permite conhecer a definição do legislador acerca da obstinação terapêutica, expressão que também enfrenta o problema de divergências conceituais que se colocam a respeito de seu conteúdo.

O Código de Deontologia Médica italiano entende obstinação terapêutica como "[...] procedimentos diagnósticos e intervenções terapêuticas desproporcionais", estabelecendo, dessa forma, uma interpretação com base na proporcionalidade do tratamento imposto ao paciente. $\mathrm{O}$ art. 16 do Código dispõe que:

Art. 16. O médico, considerando a vontade expressa pelo paciente ou por seu representante legal e os princípios de eficácia e de proporcionalidade dos cuidados não inicia nem insiste em procedimentos diagnósticos e intervenções terapêuticas clinicamente inapropriadas e eticamente não proporcionadas, das quais não se possa fundamentadamente esperar um

trattamento terapeutico non più utile alla guarigione del paziente, da cui consegue il decesso o un'anticipazione della morte del malato. Consiste quindi nella sospensione di quelle terapie e trattamenti atti a prolungare la vita che sono definite accanimento terapeutico".

39 Todas propostas encontram-se disponíveis em: <https://parlamento 17.openpolis.it/argomento_leggi/EUTANASIA/filter_act_leggi_type/DDL/filter_act_ramo/0>. 
efetivo benefício para a saúde e/ou uma melhora da qualidade de vida. O controle eficaz da dor se configura, em cada condição clínica, como o tratamento apropriado e proporcionado. $\mathrm{O}$ médico que se abstém de tratamentos não proporcionados não coloca em prática, em nenhum caso, um comportamento tendente a provocar a morte. ${ }^{40}$

É notório que as conquistas da ciência e da tecnologia permitiram a melhoria da qualidade de vida de grande parte da população mundial, no entanto, ao mesmo tempo, ao possibilitar a extensão da fase final da vida, fazem surgir novos problemas e necessidades legais que começam a delinear o denominado "direito de morrer com dignidade".

Nesse quadro de evolução da ciência, o Dossier consultivo no 392/2016 da Câmara dos Deputados (p. 4) apresenta a obstinação terapêutica como "[...] a utilização de tratamento de constatada ineficácia, ao qual se acrescenta a presença de um risco elevado ou de ulterior sofrimento ao paciente ou a utilização de um tratamento claramente desproporcional na relação risco-benefício".

As definições apresentadas pela doutrina italiana espelham esse panorama de abertura a interpretações diversificadas. Giorgio Cosmacini, conforme citado por Pasquale Rottuno (2010, p. 2), ao distinguir vida biológica de vida humana, define obstinação terapêutica como "[... ] o conjunto de tratamentos que são capazes de prolongar a vida biológica de um ser humano sem prolongar ou recuperar a sua vida humana”.

Sandro Spinsanti (1980, p. 6) trata da obstinação terapêutica como o esvaziamento da dignidade do ser humano ao possibilitar que se prolongue a vida e que se instaure "[...] o medo de tornar-se um daqueles corpos vegetativos que não acabam nunca de morrer".

Spinsanti e Francesca Petrelli (2003, p. 36) esclarecem, nesse ponto, que:

A distinção entre meios proporcionados e desproporcionados tem a vantagem de introduzir como critério para a escolha dos tratamentos uma avaliação subjetiva da vida e da sua qualidade. Uma razoável administração da própria vida pode induzir a renunciar a um tratamento que salvaria a vida ou prolongaria a existência, se isso resulta dissonante em relação ao próprio projeto de vida. A avaliação custo/benefício, de fato, não deve ser feita somente em termos econômicos, mas humano, em uma prospectiva mais ampla, que inclui os valores com base nos quais o indivíduo orienta a própria vida.

No entanto, a previsão contida no $\$ 5^{\circ}$, do art. $1^{\circ}$ do Projeto de Lei no $1142 / 2017$, permite compreender que o legislador pretende se reportar à alimentação e hidratação artificial como tratamentos disponíveis, caracterizando-os como de cunho extraordinário, nos seguintes termos:

Art. $1^{\circ}, \mathbb{S} 5^{\circ}$. Toda pessoa maior de idade e capaz tem o direito de recusar, no todo ou em

\footnotetext{
${ }^{40}$ Tradução livre de: "Art. 16. Procedure diagnostiche e interventi terapeutici non proporzionati

Il medico, tenendo conto delle volontà espresse dal paziente o dal suo rappresentante legale e dei principi di efficacia e di appropriatezza delle cure, non intraprende né insiste in procedure diagnostiche e interventi terapeutici clinicamente inappropriati ed eticamente non proporzionati, dai quali non ci si possa fondatamente attendere un effettivo beneficio per la salute e/o un miglioramento della qualità della vita. Il controllo efficace del dolore si configura, in ogni condizione clinica, come trattamento appropriato e proporzionato. II medico che si astiene da trattamenti non proporzionati non pone in essere in alcun caso un comportamento finalizzato a provocare la morte".
} 
parte, na forma do $\$ 4^{\circ}$, qualquer procedimento diagnóstico ou tratamento sanitário indicado pelo médico para a sua patologia ou de atos individualizados do próprio tratamento. Além disso, tem direito de revogar em qualquer momento, nas formas previstas no $\$ 4^{\circ}$, o consentimento prestado, mesmo quando a revogação acarretar a interrupção do tratamento, inclusive a nutrição e a hidratação artificiais. Permanece estabelecida a possibilidade para o paciente de modificar a própria vontade, a aceitação, a revogação e a recusa, que serão anotados no prontuário eletrônico. ${ }^{41}$

Nesse ponto, existem divergências e o conceito de obstinação terapêutica começa a apresentar-se com delineamento obscuro, conforme se depreende da posição de parte dos membros do Comitê Nacional de Bioética Italiano, expresso no Parecer sobre Declarações Antecipadas de Tratamento (2013) ${ }^{42}$ que, ao tratar da autonomia do paciente quanto à recusa a tratamentos, considera:

[...] que o poder dispositivo do paciente deve ser limitado, exclusivamente, àqueles tratamentos que integram, em diversas medidas, formas de obstinação terapêutica, porque desproporcionais ou, até mesmo, fúteis. Não entrariam, a seu ver, em tais hipóteses intervenções de suporte vital de caráter não extraordinário, nem alimentação, nem hidratação artificial, que, quando não resultam gravosas, constituem, ao contrário, atos eticamente e deontologicamente obrigatórios, na medida em que - proporcionadas às condições clínicas - contribuam para eliminar o sofrimento do doente terminal, cuja omissão resultaria em uma hipótese de eutanásia passiva ${ }^{43}$ (p. 11).

Diante de tantos impasses, o legislador deve ficar atento para não obstaculizar os avanços da legitimação da autodeterminação e do desenvolvimento da personalidade do indivíduo, que deve encontrar meios de atuar livremente “[...] em defesa de sua própria pessoa, considerada em seus múltiplos aspectos”.

\section{CONSIDERAÇÕES FINAIS}

Este artigo se concentrou nas questões atualmente em debate no Parlamento Italiano, fornecendo dados elaborados, sobretudo pela doutrina e pela legislação italiana, relativos à regulamentação do consentimento informado e das declarações de vontade antecipadas nos tratamentos de saúde, à luz do Projeto de Lei nº. 1.142/2017, encaminhado ao Senado, após aprovação na Câmara dos Deputados, em 20 de abril de 2017.

\footnotetext{
${ }^{41}$ Tradução livre de: "Art. 10, 5 5o. Ogni persona maggiorenne e capace di intendere e di volere ha il diritto di rifiutare, in tutto o in parte, con le stesse forme di cui al comma 4, qualsiasi accertamento diagnostico o trattamento sanitario indicato dal medico per la sua patologia o singoli atti del trattamento stesso. Ha, inoltre, il diritto di revocare in qualsiasi momento, con le stesse forme di cui al comma 4, il consenso prestato, anche quando la revoca comporti l'interruzione del trattamento, incluse la nutrizione e l'idratazione artificiali. Ferma restando la possibilità per il paziente di modificare la propria volontà, laccettazione, la revoca e il rifiuto sono annotati nella cartella clinica e nel fascicolo sanitario eletrônico".

42 Disponível em: <http://bioetica.governo.it/it/documenti/pareri-e-risposte/elenco-generale-pareri-in-ordine-cronologico/>. Acesso em: 2 set. 2017.

${ }^{43}$ Tradução livre de: "[...] che il potere dispositivo del paziente vada limitato esclusivamente a quei trattamenti che integrino, in varia misura, forme di accanimento terapeutico, perché sproporzionati o addirittura futili. Non rientrerebbero, a loro avviso, in tale ipotesi interventi di sostegno vitale di carattere non straordinario, né l'alimentazione né l'idratazione artificiale che, quando non risultino gravose per lui, costituirebbero invece, atti eticamente e deontologicamente doverosi, nella misura in cui - proporzionati alle condizioni cliniche - contribuiscono ad eliminare le sofferenze del malato terminale e la cui omissione realizzerebbe una ipotesi di eutanasia passiva".
} 
Até o momento, apenas o consentimento informado encontra-se regulamentado. No entanto, o vazio normativo quanto ao Biotestamento ainda permanece inalterado na Itália. Apontamos esse quadro de lacuna como um dos fatores que determinam a saída de italianos de seu próprio país para buscar, prevalentemente, na Suíça, a morte por meio do suicídio assistido.

Embora a discussão acerca da legalização da eutanásia e do suicídio assistido se situe distante do atual estágio de tramitação do Biotestamento, a regulamentação desse instrumento já representaria um importante avanço no direito de autodeterminação, de tal modo que o aludido documento seria capaz de dar solução a diversos casos de pacientes terminais, os quais exerceriam o direito de viver e o direito de morrer em seu próprio país.

Nesse sentido, é preciso acompanhar os passos do legislador para verificar os avanços legais que permitem - ou que limitam - a autogovernabilidade do indivíduo no respeito de sua dignidade e de sua autodeterminação pessoal no momento de terminalidade da vida.

BIOTESTAMENTO: NOTES ABOUT THE ITALIAN BILL NO. 1142/2017

\begin{abstract}
This article intends to demonstrate the Italian experience regarding the legal instruments of patient selfdetermination in the end-of-life choices, according to the understanding of Italian Bill No. 1142/2017 on the regulation of the Biotestamento, approved in April 2017 in the Chamber of Deputies and currently under discussion in the Italian Senate. The proposal to introduce into the Italian legal system the institute of Biotestamento is relevant on the basis of concrete cases, which reignite the debates on the right of selfdetermination. It is, therefore, interesting to follow the discussion about this bill, by means of a bibliographical research, highlighting concepts and debates that gravitate the theme, within the perspective of Italian authors and institutions interested in the subject.
\end{abstract}

Keywords: Self-determination. Regulation. Biotestamento. Italian bill. End of life decisions.

\title{
REFERENCIAS
}

COMITATO NAZIONALE PER LA BIOETICA. Parere dichiarazioni anticipate di trattamento del 18 dicembre de 2003. Disponível em: <http://bioetica.governo.it/it/documenti/pareri-e-risposte/elencogenerale-pareri-in-ordine-cronologico/>. Acesso em: 2 set. 2017.

FEDERAZIONE NAZIONALE DEGLI ORDINI DEI MEDICI CHIRURGHI E DEGLI ODONTOIATRI.

Codice di Deontologia Medica di 2014. Disponível em: $<$ https://portale.fnomceo.it/fnomceo/Codice+di+Deontologia + Medica+2014.html?t=a\&id=115184>. Acesso 
em: 15 set. 2017.

FELICI, Alessandro. Consenso informato: riflessioni di um medico paziente. Milano: Librati, 2008.

ITÁlIA. Câmara dos Deputados. Proposta di legge no 1142/2017. Disponível em: $<$ http://www.camera.it/_dati/leg17/lavori/stampati/pdf/17PDL0050240.pdf >. Acesso em: 5 ago. 2017.

Senado Italiano. Atto Senato $n^{\text {o }}$ 2801/2017. Disponível em: <http://www.senato.it/leg/17/BGT/Schede/Ddliter/47964.htm>. Acesso em: 2 set. 2017.

Corte Constitucional Italiana. Sentenza $n^{o}$. 438 del 2008. Disponível em: <http://documenti.camera.it/Leg17/Dossier/Pdf/COST252.Pdf>. Acesso em: 15 set. 2017.

MATERSTVEDT, Lars Johan, et al. Eutanasia e suicidio assistito dal medico: il punto di vista di una task force sull'etica dell'EAPC. Rivista italiana di cure palliative, Milano, v. 6, n. 1, p. 42-46, 2004.

MIRABELLI, Cesare. Audizione alla commissione sanità del Senato, 2017. Disponível em: $<$ http://www.senato.it/leg/17/BGT/Schede/Ddliter/documenti/47964_documenti.htm>. Acesso em: 11 set. 2017.

PIZZETTI, Federico G. Alle frontiere della vita: il testamento biologico tra valori costituzionali e promozione della persona. Milano: Giuffré Editore, 2008.

ROTTUNO, Pasquale. Testamento biologico, il punto di vista del medico e filosofo Giorgio Cosmacini: fra dignità e sacralità della vita. Rivista L'Avanti!, Roma, 2010. Disponível em: <https://www.medicinaepersona.org/old/resources/articolo/

N1280629c52e95fbd915/N1280629c52e95fbd915/05-fra_dignit_e_sacralit_della_vita.pdf $>$. Acesso em: 2 set. 2017.

SOCIETÀ ITALIANA DI CURE PALLIATIVE (SICP). Documento sulle direttive anticipate. Versão de 911-2006. Disponível em: < http://www.sicp.it/web/eventi/SICP/documenti.cfm>. Acesso em: 3 set. 2017.

SPISANTI, Sandro. Umanizzare la malattia e la morte. Milano: Paoline, 1980.

SPISANTI, Sandro. PETRELLI, Francesca. Scelte etiche ed eutanasia. Milano: Paoline, 2003.

VERONESI, Umberto. Testamento biologico: una scelta consapevole. Milano: Fondazione Umberto Veronesi, 2007.v.2.

Trabalho enviado em 03 de outubro de 2017.

Aceito em 18 de janeiro de 2018. 